\title{
A View of Diel Variation of Maize Odorscape
}

\author{
Ene Leppik1, Toomas Tammaru², Brigitte Frérot ${ }^{1}$ \\ ${ }^{1}$ French National Institute for Agricultural Research, Versailles Cedex, France \\ ${ }^{2}$ University of Tartu, Tartu, Estonia \\ Email: brigitte.frerot@versailles.inra.fr
}

Received 8 January 2014; revised 9 February 2014; accepted 28 February 2014

Copyright (C) 2014 by authors and Scientific Research Publishing Inc.

This work is licensed under the Creative Commons Attribution International License (CC BY). http://creativecommons.org/licenses/by/4.0/

(c) (1) Open Access

\section{Abstract}

Volatile organic compounds (VOCs) released by host plants attract gravid European corn borer (ECB) female moths for oviposition. Despite extensive studies, little is known about VoCs emitted by maize under natural conditions or the odorscape of a maize field, particularly at the time of ECB oviposition. Here, we characterized VOCs released by undamaged maize plants and VOCs in the maize field odorscape. VOCs were collected throughout the diel cycle with solid-phase microextraction fibres. VOCs were identified by GC-MS and quantified with calibration curves. Four replicates per time period were collected; i.e., dusk, night, dawn, and day. VOC patterns differed between the maize plants and the maize field odorscape throughout the diel cycle. At night, the period of ECB oviposition, the VOC pattern was characterized by an increase in monoterpenes, a decrease in sesquiterpenes, and the presence of methyl salicylate, $\alpha$-copaene, and Z-3-hexenyl acetate. An apparent discrepancy between maize plant and field odorscape VOC compositions was observed. Key compounds were identified as putative host-cues, including methyl salicylate, $\alpha$-pinene, 3-carene, p-cymene, limonene, and dimethyl nonatriene. This study showed that VOCs were released by maize in a diel pattern, and host-characteristic cues were present for nocturnal ECB oviposition.

\section{Keywords}

European Corn Borer; Oviposition; GC-MS; SPME; Maize Pest; VOCs; Field Odorscape

\section{Introduction}

Insect and plants through co-evolution forged close ties, often based on perception by insect of chemical signals emitted by the plant [1] [2]. Although not being a native plant of Europe, the cultivated maize (Zea mays, L.) has been colonized by a native herbivore Lepidoptera, the ECB. Being cultivated yearly over large areas, maize offers an inexhaustible food resource, often leading to uncontrolled ECB population growth. 
ECB is a nocturnal behaving insect which mate in dense grassy area where they rest and hide during the day [3] [4]. Host plant recognition is achieved by gravid ECB females seeking for oviposition sites shortly after sunset [4]. Field observations clearly showed that the gravid ECB females reach maize fields by oriented flights from the resting area (Frérot \& Leppik, unpublished data), flying up the prevailing wind, which is likely carrying maize filed odors.

Previous studies on volatile organic compounds (VOCs) released by maize were mostly conducted under laboratory conditions using isolated and cut plants, to identify herbivore-damaged or wounded plant induced VOCs that attract natural enemies [5]-[8]. Other studies focusing on identification of the maize VOCs were carried out during the photophase under laboratory conditions [9]. Only two papers report on diel pattern of VOCs collected on water stressed maize [10] and on herbivore attacked maize [11]: both studies were conducted under laboratory conditions on small potted plants. All the other information on maize VOCs was dealing with genetic variation [12], environmental conditions and growth stage [7]. They lead to identification of 40 maize VOCs and have shown that maize is rather poor in volatiles compared to other ECB host plants like hop or mugwort [13].

Regardless of numerous studies on maize emitted VOCs, little is known about the maize VOCs released in situ under field conditions. VOCs profiles obtained under the photophase are thus probably not relevant to nocturnal host seeking moth. The natural odorscape encountered by the nocturnal host seeking ECB remain unknown. The aim of this study was to provide an ecologically relevant insight into the natural plant produced VOCs at the scales of the plant and the field during the period of ECB activity. VOCs were collected from maize plant headspaces and from field atmosphere. The collected VOCs were identified and quantified. The differences between VOCs blend from maize plant headspace and field atmosphere are discussed based on the present knowledge of the chemistry of emitted VOCs and their ecological significance.

\section{Materials and Methods}

\subsection{Sampling Site}

The experiments were conducted in a maize field situated in the Ile-de-France region near Grignon (Yvelines) ( $\left.48^{\circ} 85^{\prime} \mathrm{N}, 1.9^{\circ} 68^{\prime} \mathrm{E}\right)$ in France. The plant was represented by the variety Troubadour, a commonly cultivated maize cultivar in the northern part of France. The maize field consisted of approximately 15 ha of continuous cropland with no industrial sources of VOC. The collections were conducted from 10 June to 16 June 2010 , from 22 June to 23 June 2010 and from 25 June to 26 June 2010. Maize plants were at the four-leaf phenological stage [14]. Temperature from dusk till dawn varied from $9^{\circ} \mathrm{C}$ to $18^{\circ} \mathrm{C}$ and $\mathrm{RH} \%$ from $74 \%$ to $100 \%$. Throughout the collection session, there was neither precipitation nor strong winds.

\subsection{VOC Collections}

The non-destructive static headspace-sampling mode was chosen for collecting maize VOCs. Plants were chosen so as to have approximately equal leaf surfaces; they were enclosed into individual Teflon bags $(50 \times 25 \mathrm{~cm})$. A small hole was pierced to the Teflon bag to introduce a Solid Phase Micro Extraction (SPME) fiber. Control samples, one per time periods, constituted of an empty closed Teflon bag with a SPME fiber introduced under the same condition as the plants. Headspace VOCs were collected during two hours at four distinct time periods: dusk (22:00 - 00:00), night (01:00 - 03:00), dawn (05:00 - 07:00) and day (13:00 - 15:00). After VOCs collection, SPME fibers were packed individually into aluminum foils and stored at $-20^{\circ} \mathrm{C}$ until gas chromatography (GC) and mass spectrometry (MS) analyses. For every collection a new plant was chosen. Two replicates for each time period were collected on two different days and nights implying that VOCs profiles from 16 plants were recorded altogether.

Maize field atmosphere VOCs were collected by placing SPME fibers in open-air condition, in the middle of the maize field. The fiber was attached at the top part of a maize stem and VOCs were collected under the same conditions as described above for the static headspace. Maize field atmosphere VOCs were collected during two hours at four distinct time periods: dusk (22:00 - 00:00), night (01:00 - 03:00), dawn (05:00 - 07:00) and day (13:00 - 15:00) from the same field where the headspace VOCs collections took place.

\subsection{SPME Fiber}

SPME fibers DVB/CARBOXEN/PDMS 50/30 $\mu \mathrm{m}$ (Supelco) were used. Prior to each sampling, fibers were 
cleaned by heating in the GC injector at $250^{\circ} \mathrm{C}$ for $5 \cdot$ min with helium as gas flow. Cleaned fibers were wrapped into aluminum foil and stored in screw-capped individual Pyrex glass tubes until they were used.

\subsection{Chemical Analyses}

To identify the maize headspace and field atmosphere VOCs the SPME fibers were desorbed in the Varian 3400 GC injector held at $250^{\circ} \mathrm{C}$. The GC was linked to a MS detector Varian QIMS. Compound separation was carried out using Rxi-5ms column (Restek, France) $30 \mathrm{~m} \times 0.32 \mathrm{~mm}$ i.d., film thickness $1.0 \mu \mathrm{m}$ ). The column was programmed to hold at $50^{\circ} \mathrm{C}$ for 3 minutes and to increase at $8^{\circ} \mathrm{C} / \mathrm{min}$ to $300^{\circ} \mathrm{C}$. Helium was used as carrier gas. Mass spectra were obtained in electron impact mode $(70 \mathrm{eV})$ with the ion source at $230^{\circ} \mathrm{C}$ in a full scan mode (30 - 400 uma).

VOCs eluted from SPME collections were identified according to their mass spectra and retention indexes (RI). The RIs were computed using n-alkanes from C10 to C24, eluted under the same conditions as the samples. Every compound spectra and RI were compared with the RI and spectra of laboratory and NIST 1998 libraries using deconvolution software AMDIS32.

The calibration curves of GLV, MT and sesquiterpenes (SQT) were obtained by injection of the following synthetic samples: linalool, $\alpha$-pinene, $\alpha$-humulene, $\alpha$-copaene, MeSA, cis-3-hexenol (Z3-6:OH), (Sigma-Aldrich), $\beta$-farnesene (Chemtech), ocimene (Fluka) and cis-3-hexenyl acetate (Z3-6:Ac) (Lancaster). Each compound was injected at least in three replicates at the concentrations of 5, 10, 25 and $50 \mathrm{ng} / \mu \mathrm{l}$. Linear calibration curves were created for each compound to estimate the GC-MS ion trap detector response. The GC-MS detector response for linalool, ocimene and myrcene were used to quantify the acyclic MT, $\alpha$-pinene for cyclic MT, $\alpha$-humulene and $\alpha$-copaene for cyclic SQT, $\beta$-farnesene for acyclic sesquiterpenes, MeSA, Z3-6:OH and Z36:Ac responses were used to quantify the different GLV.

\subsection{Data Analyses}

All the raw GC data of VOCs areas were transformed in nanograms (ng) using respective authentic calibration curves. Relative amount of compounds was calculated by dividing the compound amount (ng) by the total amount of detected compounds in the same analysis and expressed as a percentage.

When studying the diel cycle of emitted volatile compounds, we had four replicates of VOCs profiles for each of the time periods and two replicates for air collections from the maize fields.

To study if there was a difference between the time periods in the composition of the volatile compounds, a straightforward MANOVA approach, i.e. treating the amount of each compound as a dependent variable was not feasible due to insufficient number of degrees of freedom. To reduce dimensionality, we conducted a principal component (PCA) with total spectrum of the volatile compounds. A MANOVA was then performed on the values of respective PC scores. Taken separately, the first three PC were tested with two-way ANOVAs to access if there is a significant difference between time periods. Analogous analyses were performed separately for SQT, and all compounds other than SQT. For all ANOVAs, distributions of residuals were checked and no substantial deviations from normality were found. The analysis of among-period differences of individual compounds were compared among the three periods using non-parametric Kruskal-Wallis test as clear deviations from normality precluding a parametric ANOVA approach was evidenced among-period differences of individual compounds. An analogous MANOVA PC analysis and Kruskal-Wallis test were conducted on field air VOCs data.

\section{Results}

\subsection{Maize Headspace VOCs}

From maize headspace VOCs collections, 21 components were detected and identified according to the retention index and comparison of the mass spectra with authentic samples or respective data bases (Table 1). 19 components out of 21 were already identified at least once in different studies dealing with maize VOCs. Two VOCs were newly identified as maize VOCs: p-cymene, and a compound tentatively identified as selina-3,7 (11) diene (SQT).

Maize odour was found to be a mixture of three GLVs, six MT, two HT and 12 SQT (Table 1) the amount of which varies considerably throughout the 24-hour cycle. The relative ratios of MT and SQT changed between day and night (Figure 1). The peak of SQT emission occurred during the day. In contrast, the peak of MT emis- 
Table 1. Mean relative ratios of VOCs identified from maize headspace volatile collections. Values are expressed as percentage relative to total VOCs.

\begin{tabular}{|c|c|c|c|c|c|c|c|c|c|c|c|c|}
\hline & & & \multicolumn{10}{|c|}{ Individual maize VOCs } \\
\hline & & & \multicolumn{2}{|l|}{ Day $(n=4)$} & \multicolumn{2}{|l|}{ Dusk $(n=4)$} & \multicolumn{2}{|c|}{ Night $(n=4)$} & \multicolumn{2}{|c|}{ Dawn $(n=4)$} & \multicolumn{2}{|c|}{ Kruskal-Wallis } \\
\hline & & & & & & $\mathbf{R e}$ & ative amount & $(\%)$ & & & & \\
\hline \multirow[t]{2}{*}{ RI } & VOCs & & Mean \pm SE & $\mathrm{O}$ & Mean \pm SE & $\mathrm{O}$ & Mean \pm SE & $\mathrm{O}$ & Mean \pm SE & $\mathrm{O}$ & $\mathrm{Chi}^{2}$ & p-value \\
\hline & Green leaf volatiles & & & & & & & & & & & \\
\hline 860 & Cis-3-hexenol [8] [9] [13] [20]* & $\mathrm{rt} / \mathrm{MS}$ & $6.82 \pm 5.35$ & 2 & $20.58 \pm 3.31$ & 4 & 6.86 & 1 & 9.11 & 1 & 3.366 & 0.339 \\
\hline 1007 & $\begin{array}{l}\text { Cis-3-hexenyl acetate } \\
\text { [8] [9] [13] [28] [29] }\end{array}$ & $\mathrm{rt} / \mathrm{MS}$ & - & & $1.15 \pm 0.48$ & 3 & $3.28 \pm 2.61$ & 3 & - & & 8.454 & 0.038 \\
\hline \multirow[t]{2}{*}{1209} & MeSA [9] [13] [20] [29]* & $\mathrm{rt} / \mathrm{MS}$ & $27.92 \pm 11.21$ & 4 & $12.30 \pm 0.77$ & 4 & $18.13 \pm 3.14$ & 4 & $34.15 \pm 4.22$ & 4 & 6.199 & 0.102 \\
\hline & Monoterpenes & & & & & & & & & & & \\
\hline 942 & $\alpha$-pinene [13] [29] ${ }^{*}$ & $\mathrm{rt} / \mathrm{MS}$ & $4.20 \pm 3.04$ & 2 & $4.08 \pm 1.76$ & 3 & $8.12 \pm 3.21$ & 3 & $12.91 \pm 4.76$ & 3 & 3.295 & 0.348 \\
\hline 993 & $\beta$-myrcene [8] [13] [20]* & $\mathrm{rt} / \mathrm{MS}$ & 0.25 & 1 & - & & - & & - & & 3.000 & 0.392 \\
\hline 1017 & 3-carene* & $\mathrm{rt} / \mathrm{MS}$ & - & & - & & $2.85 \pm 1.67$ & 2 & 1.71 & 1 & 3.845 & 0.279 \\
\hline 1032 & p-cymene ${ }^{*}$ & $\mathrm{rt} / \mathrm{MS}$ & $6.92 \pm 5.2$ & 3 & $7.05 \pm 2.75$ & 2 & $11.09 \pm 2.86$ & 4 & $12.55 \pm 1.95$ & 4 & 4.993 & 0.172 \\
\hline 1038 & Limonene $^{*}$ & $\mathrm{rt} / \mathrm{MS}$ & $4.54 \pm 2.94$ & 3 & $4.96 \pm 3.23$ & 2 & $18.02 \pm 9.6$ & 3 & $13.22 \pm 5.68$ & 3 & 2.568 & 0.463 \\
\hline \multirow[t]{2}{*}{1098} & $\alpha$-linalool [8] [9] [13] [28] [29] & $\mathrm{rt} / \mathrm{MS}$ & - & & - & & - & & - & & - & - \\
\hline & Homoterpenes & & & & & & & & & & & \\
\hline 1117 & DMNT [8] [13] [20] $]^{*}$ & $\mathrm{rt} / \mathrm{MS}$ & 2.29 & 1 & $1.77 \pm 0.11$ & 4 & $0.92 \pm 0.5$ & 3 & 0.02 & 1 & 6.058 & 0.109 \\
\hline \multirow[t]{2}{*}{1128} & TMTT [8] [28] & $\mathrm{rt} / \mathrm{MS}$ & $0.77 \pm 0.77$ & 2 & - & & - & & - & & 6.400 & 0.094 \\
\hline & Sesquiterpenes & & & & & & & & & & & \\
\hline 1395 & $\alpha$-copaene [9] [13] & $\mathrm{rt} / \mathrm{MS}$ & $22.01 \pm 9.47$ & 3 & $33.65 \pm 6.18$ & 4 & $30.7 \pm 9.68$ & 4 & $16.29 \pm 7.02$ & 3 & 3.474 & 0.324 \\
\hline 1415 & Ylangene [9] [28] & NIST & 0.46 & 1 & - & & - & & - & & 3.000 & 0.392 \\
\hline 1450 & $\begin{array}{c}\text { Trans- } \alpha \text {-bergamotene } \\
\text { [8] [20] [28] [30] }\end{array}$ & NIST & $2.30 \pm 1.76$ & 2 & $5.27 \pm 0.09$ & 4 & - & & - & & 10.252 & 0.017 \\
\hline 1452 & $\begin{array}{c}\beta \text {-caryophyllene } \\
\text { [8] [9] [13] [20] [28]-[30]* }\end{array}$ & $\mathrm{rt} / \mathrm{MS}$ & 1.37 & 1 & - & & - & & - & & 3.000 & 0.392 \\
\hline 1464 & $\begin{array}{c}\beta \text {-farnesene } \\
{[8][9][13][20][28][30]^{*}}\end{array}$ & $\mathrm{rt} / \mathrm{MS}$ & 0.10 & 1 & 0.02 & 1 & - & & - & & 2.150 & 0.542 \\
\hline 1516 & GermacreneD [9] [28] [30] & $\mathrm{rt} / \mathrm{MS}$ & 0.46 & 1 & - & & - & & - & & 3.000 & 0.392 \\
\hline 1527 & $\gamma$-cadinene [13] [30] & $\mathrm{rt} / \mathrm{MS}$ & - & & 1.25 & 1 & - & & - & & 3.000 & 0.392 \\
\hline 1535 & $\delta$-cadinene [13] [30] & $\mathrm{rt} / \mathrm{MS}$ & 0.47 & 1 & $2.57 \pm 1.48$ & 2 & - & & - & & 4.604 & 0.203 \\
\hline 1544 & Selina-3,7 (11) diene & NIST & 0.42 & 1 & & & - & & - & & 3.000 & 0.392 \\
\hline 1549 & $\alpha$-cadinene [13] [30] & $\mathrm{rt} / \mathrm{MS}$ & 0.43 & 1 & $5.28 \pm 0.17$ & 4 & - & & - & & 12.913 & 0.005 \\
\hline 1592 & Trans-nerolidol [8] [13] [20] [28] & $\mathrm{rt} / \mathrm{MS}$ & $18.20 \pm 11.48$ & 2 & 3.27 & 1 & - & & - & & 4.604 & 0.203 \\
\hline
\end{tabular}

RI-retention index; rt/MS-identification by retention time and mass spectra, NIST-tentative identification by NIST11; SE-standard error; O-occurrence (i.e. the number of analyses in which the compounds was detected), ${ }^{*}$ compounds active on the antennae of EAG according to literature [10] [31]. The numbers in superscript after the VOC refers to the paper where it is identified as maize VOC.

sion was observed during night and dawn. HT was always present in low quantity and did not change substantially in time. GLV diel composition was characterized by the absence of Z3-6:Ac during day and at dawn, whereas the relative amount of Z3-6:OH increased during dusk. 
MeSA and $\alpha$-copaene, were the two main compounds in maize headspace collections and accounted for half of the relative amount of all the VOCs detected. The ratio of relative amounts of MeSA and $\alpha$-copaene varied in time (Table 1).

The three PC calculated from the measured amounts of VOC explained 35\%, 21\% and $14 \%$ of variance respectively. A MANOVA performed on the values of the three PC revealed a significant difference in the ratio of maize VOCs between the four time periods (Wilk's lambda $=0.071, \mathrm{p}=0.0015$ ). When the three PC's were analysed separately, only the scores of PC2 differed significantly between the time periods (two-way ANOVA with date as an additional factor: F 3, $11=15.7, \mathrm{p}=0.0002$ ) and captured the time-related variance of VOC ratio (Figure 2). Pairwise comparisons of PC2 scores among the four periods showed that there is no significant difference between maize VOCs ratios of day and dusk, and night and dawn, respectively. All other comparisons returned a significant difference (Tukey test: $\mathrm{p}<0.02$ ).

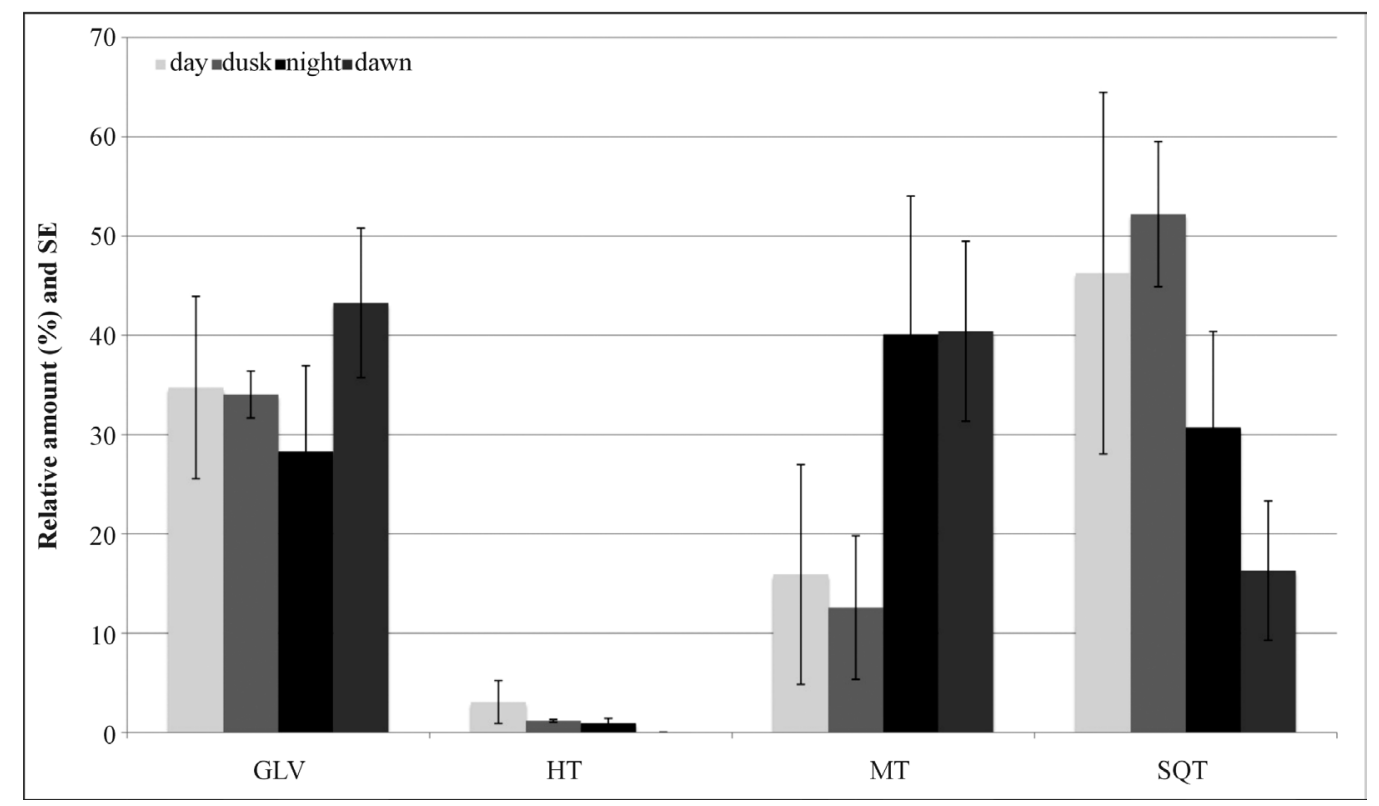

Figure 1. The diel changes in relative amounts of GLV, HT, MT and SQT from maize headspace samples $(n=4)$.

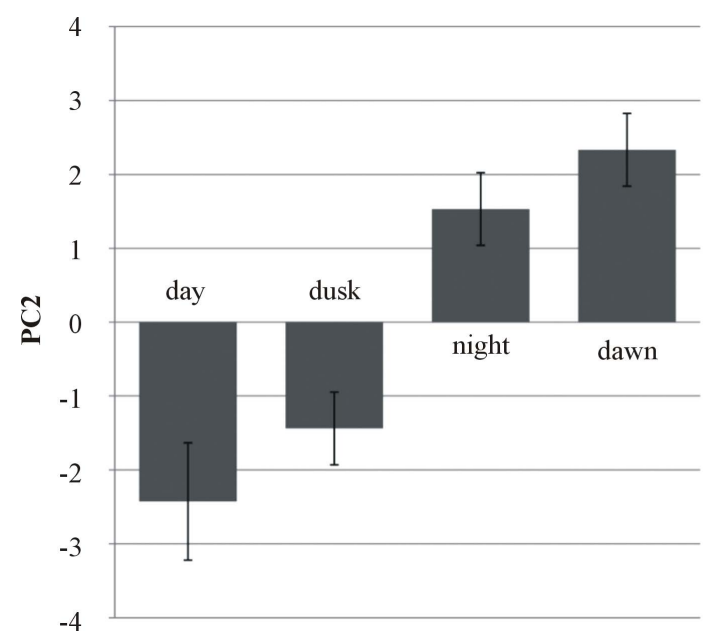

Figure 2. Principal component bi-plot of maize headspace VOCs. The variations in VOC composition and relative amounts distinguish day and dusk from night and dawn. 
Analogous analyses were performed on the headspace VOC data separately by classes of compounds (Table 2). We found that the profiles of SQT differed between the time periods (Wilk's lambda $=0.060, p=0.006$ ), with again, the profiles of night and dawn, as well as day and dusk, being similar to each other, and most pairwise contrasts among the time points attaining significance. In contrast, no among-period differences could be shown for the rest of the compounds (Wilk's lambda $=0.27, \mathrm{p}=0.15$ ) i.e. GLV, HT, MT.

The analysis of among-period differences of individual VOCs was performed using Kruskal-Wallis test (Table 1). In the individual maize static headspace collections, the diel relative amount of 3 VOCs out of 21 changed significantly (Z3-6:Ac ( $\mathrm{df}=3, \mathrm{~N}=16, \mathrm{Z}=8.45, \mathrm{p}=0.038)$, trans- $\alpha$-bergamotene $(\mathrm{df}=3, \mathrm{~N}=16, \mathrm{Z}=$ $10.25, \mathrm{p}=0.017$ ), $\alpha$-cadinene ( $\mathrm{df}=3, \mathrm{~N}=16, \mathrm{Z}=12.91, \mathrm{p}=0.005$ ). Pairwise comparison for the GLV Z3-6:Ac showed that the relative ratio did not change significantly in time ( $\mathrm{p} \geq 0.05)$. Additionally, Z3-6:Ac was detected only at dusk and night in maize VOCs collections.

Trans- $\alpha$-bergamotene and $\alpha$-cadinene were not detected during night and dawn and were found present only during the photophase with a significantly higher amount during dusk $(\mathrm{p}=0.038, \mathrm{Z}=8 ; \mathrm{p}=0.013, \mathrm{Z}=8.500$ respectively).

\subsection{Field Odorscape VOCs}

In the maize field atmosphere a total of 13 VOCs were detected and identified (Table 3). The VOCs profile was dominated by MeSA and a complex of p-cymene with limonene and constant low levels of DMNT. The ratio of MeSA to the complex of p-cymene-limonene did not change with the diel period; $\alpha$-pinene, 3-carene, linalool and $\alpha$-copaene, $\beta$-farnesene, trans-nerolidol were detected in a random manner in the atmosphere without no clear diel pattern.

The relative amounts of the 13 VOCs detected in the maize field analyze did not changed significantly in time. Also when these 13 VOCs were grouped in chemical classes, no significant diel variation was observed in relative amounts (Kruskal Wallis test, $\mathrm{p} \geq 0.05$ for all cases) (Table 3).

\subsection{Maize Headspace versus Field Atmosphere VOCs}

The samples from maize field atmosphere and maize headspace shared 12 VOCs. Out of the 13 VOCs detected in the maize field atmosphere, the repeatedly detected MT alcohol linalool was the only VOC, never found in maize headspace. The VOC profiles from maize headspaces were considerably richer in VOCs than the air samples from the field. The individual maize VOCs blend was mainly composed of SQT, as for the maize field atmosphere was composed predominantly of MT. In general, the pattern of diel changes in VOCs composition of individual maize and maize field atmosphere did not match. Solely MeSA (GLV) had the same diel pattern of emission in field and headspace collections with the emission peak during the day time of the 24-hours cycle and the decrease during dusk and night.

\section{Discussion}

Working in the field on healthy maize plants generates a new description of volatiles released by maize and for

Table 2. Mean relative ratios of VOCs grouped into chemical classes. Values are expressed as percentage relative to total VOCs.

\begin{tabular}{|c|c|c|c|c|c|c|c|c|c|c|c|c|}
\hline & \multicolumn{12}{|c|}{ Relative amount (\%) } \\
\hline \multirow{3}{*}{$\begin{array}{l}\text { VOCs } \\
\text { classes }\end{array}$} & \multicolumn{6}{|c|}{ Maize headspace } & \multicolumn{6}{|c|}{ Maize field atmosphere } \\
\hline & \multirow{2}{*}{$\begin{array}{l}\text { Day }(n=4) \\
\text { Mean } \pm \text { SE }\end{array}$} & \multirow{2}{*}{$\begin{array}{l}\text { Dusk }(n=4) \\
\text { Mean } \pm \text { SE }\end{array}$} & \multirow{2}{*}{$\begin{array}{c}\text { Night }(n=4) \\
\text { Mean } \pm \text { SE }\end{array}$} & \multirow{2}{*}{$\begin{array}{c}\text { Dawn }(n=4) \\
\text { Mean } \pm \text { SE }\end{array}$} & \multicolumn{2}{|c|}{ Kruskal-Wallis } & \multirow{2}{*}{$\begin{array}{l}\text { Day }(n=2) \\
\text { Mean } \pm \text { SE }\end{array}$} & \multirow{2}{*}{$\begin{array}{c}\text { Dusk }(n=3) \\
\text { Mean } \pm \text { SE }\end{array}$} & \multirow{2}{*}{$\begin{array}{l}\text { Night }(n=4) \\
\text { Mean } \pm \text { SE }\end{array}$} & \multirow{2}{*}{$\begin{array}{c}\text { Dawn }(\mathrm{n}=3) \\
\text { Mean } \pm \text { SE }\end{array}$} & \multicolumn{2}{|c|}{ Kruskal-Wallis } \\
\hline & & & & & $\mathrm{Chi}^{2}$ & $\mathrm{p}$-value & & & & & $\mathrm{Chi}^{2}$ & $\mathrm{p}$-value \\
\hline GLV & $34.74 \pm 9.18$ & $34.04 \pm 2.36$ & $28.28 \pm 8.66$ & $43.27 \pm 7.52$ & 1.522 & 0.677 & $41.57 \pm 26.68$ & $30.10 \pm 7.46$ & $25.33 \pm 8.73$ & $34.35 \pm 6.24$ & 0.737 & 0.864 \\
\hline MT & $15.91 \pm 11.07$ & $12.57 \pm 7.24$ & $40.09 \pm 13.94$ & $40.40 \pm 9.06$ & 5.374 & 0.146 & $55.07 \pm 23.80$ & $62.78 \pm 4.12$ & $56.41 \pm 4.21$ & $60.34 \pm 3.89$ & 0.853 & 0.837 \\
\hline HT & $3.06 \pm 2.15$ & $1.17 \pm 0.12$ & $0.92 \pm 0.50$ & $0.01 \pm 0.02$ & 5.727 & 0.126 & $3.34 \pm 2.88$ & $0.81 \pm 0.68$ & $1.87 \pm 1.00$ & $1.77 \pm 1.16$ & 1.768 & 0.622 \\
\hline SQT & $46.27 \pm 18.20$ & $52.20 \pm 7.29$ & $30.69 \pm 9.68$ & $16.29 \pm 7.02$ & 5.749 & 0.124 & $0.00 \pm 0.00$ & $6.29 \pm 6.29$ & $16.37 \pm 10.11$ & $3.51 \pm 3.51$ & 1.942 & 0.584 \\
\hline
\end{tabular}


Table 3. Mean relative ratios of VOCs identified from maize field volatile collections. Values are expressed as percentage relative to total VOCs.

\begin{tabular}{|c|c|c|c|c|c|c|c|c|c|c|c|c|}
\hline & & & \multicolumn{10}{|c|}{ Maize field ambient air VOCs } \\
\hline & & & \multicolumn{2}{|c|}{ Day $(\mathrm{n}=2)$} & \multicolumn{2}{|c|}{ Dusk $(\mathrm{n}=3)$} & \multicolumn{2}{|c|}{ Night $(n=4)$} & \multicolumn{2}{|c|}{ Dawn $(\mathrm{n}=3)$} & \multicolumn{2}{|c|}{ Kruskal-Wallis } \\
\hline & & & & & & & lative amount & $(\%)$ & & & & \\
\hline \multirow[t]{2}{*}{ RI } & VOCs & & Mean \pm SE & $\mathrm{O}$ & Mean \pm SE & $\mathrm{O}$ & Mean \pm SE & $\mathrm{O}$ & Mean \pm SE & $\mathrm{O}$ & $\mathrm{Chi}^{2}$ & $p$-value \\
\hline & Green leaf volatiles & & & & & & & & & & & \\
\hline 860 & Cis-3-hexenol [8] [9] [13] [20] & $\mathrm{rt} / \mathrm{MS}$ & - & & - & & - & & - & - & - & - \\
\hline 1007 & $\begin{array}{l}\text { Cis-3-hexenyl acetate } \\
\text { [8] [9] [13] [28] [29] }\end{array}$ & $\mathrm{rt} / \mathrm{MS}$ & - & & - & & 0.11 & 1 & - & - & 2.000 & 0.572 \\
\hline \multirow[t]{2}{*}{1209} & $\operatorname{MeSA}[9][13][20][29]^{*}$ & $\mathrm{rt} / \mathrm{MS}$ & $41.57 \pm 26.68$ & 2 & $30.10 \pm 7.46$ & 3 & $25.21 \pm 8.63$ & 4 & $34.35 \quad 6.24$ & 3 & 0.737 & 0.864 \\
\hline & Monoterpenes & & & & & & & & & & & \\
\hline 942 & $\alpha$-pinene [13] [29] ${ }^{*}$ & $\mathrm{rt} / \mathrm{MS}$ & - & & $13.05 \pm 7.50$ & 2 & $3.65 \pm 2.13$ & 2 & $9.68 \pm 4.85$ & 2 & 3.389 & 0.335 \\
\hline 993 & $\beta$-myrcene $[8][13][20]^{*}$ & $\mathrm{rt} / \mathrm{MS}$ & - & & 2.00 & 1 & $9.63 \pm 5.58$ & 2 & 2.59 & 1 & 1.942 & 0.584 \\
\hline 1017 & 3-carene ${ }^{*}$ & $\mathrm{rt} / \mathrm{MS}$ & 3.18 & 1 & 3.80 & 1 & $1.63 \pm 1.07$ & 2 & - & & 1.838 & 0.607 \\
\hline 1032 & p-cymene ${ }^{*}$ & $\mathrm{rt} / \mathrm{MS}$ & $28.95 \pm 2.31$ & 2 & $11.70 \pm 6.04$ & 2 & $18.86 \pm 9.37$ & 4 & $13.84 \pm 4.19$ & 3 & 3.013 & 0.390 \\
\hline 1038 & Limonene $^{*}$ & $\mathrm{rt} / \mathrm{MS}$ & 2.95 & 1 & $19.90 \pm 2.25$ & 3 & $9.99 \pm 4.20$ & 3 & $19.35 \pm 6.94$ & 3 & 6.550 & 0.088 \\
\hline \multirow[t]{2}{*}{1098} & Linalool [8] [9] [13] [28] [29] & $\mathrm{rt} / \mathrm{MS}$ & 19.97 & 1 & 12.32 & 1 & $12.62 \pm 8.33$ & 2 & 14.87 & 1 & 0.295 & 0.961 \\
\hline & Homoterpenes & & & & & & & & & & & \\
\hline 1117 & DMNT [8] [13] [20]* & $\mathrm{rt} / \mathrm{MS}$ & $3.34 \pm 2.88$ & 2 & $0.81 \pm 0.68$ & 2 & $1.87 \pm 1.00$ & 3 & $1.77 \pm 1.16$ & 2 & 1.768 & 0.622 \\
\hline \multirow[t]{2}{*}{1128} & TMTT [8] [28] & $\mathrm{rt} / \mathrm{MS}$ & - & & - & & - & & - & & & - \\
\hline & Sesquiterpenes & & & & & & & & & & & \\
\hline 1395 & $\alpha$-copaene [9] [13] ${ }^{*}$ & $\mathrm{rt} / \mathrm{MS}$ & - & & 3.42 & 1 & - & & 3.51 & 1 & 2.212 & 0.530 \\
\hline 1415 & Ylangene [9] [13] & NIST & - & & - & & - & & - & & & - \\
\hline 1450 & $\begin{array}{c}\text { Trans- } \alpha \text {-bergamotene } \\
\text { [8] [20] [28] [30] }\end{array}$ & NIST & - & & - & & - & & - & & & - \\
\hline 1452 & $\begin{array}{c}\beta \text {-caryophyllene } \\
{[8][9][13][20][28]-[30]^{*}}\end{array}$ & $\mathrm{rt} / \mathrm{MS}$ & - & & - & & - & & - & & & - \\
\hline 1464 & $\begin{array}{c}\beta \text {-farnesene } \\
{[8][9][13][20][28][30]^{*}}\end{array}$ & $\mathrm{rt} / \mathrm{MS}$ & - & & - & & $0.21 \pm 0.12$ & 2 & - & & 4.364 & 0.225 \\
\hline 1516 & GermacreneD [9] [28] [30] & $\mathrm{rt} / \mathrm{MS}$ & - & & - & & - & & - & & & - \\
\hline 1527 & $\gamma$-cadinene [13] [30] & $\mathrm{rt} / \mathrm{MS}$ & - & & - & & - & & - & & & - \\
\hline 1535 & $\delta$-cadinene [13] [30] & $\mathrm{rt} / \mathrm{MS}$ & - & & 2.86 & 1 & - & & - & & 3.000 & 0.392 \\
\hline 1544 & Selina-3,7 (11) diene & NIST & - & & - & & - & & - & & & - \\
\hline 1549 & $\alpha$-cadinene [13] [30] & $\mathrm{rt} / \mathrm{MS}$ & - & & - & & - & & - & & & - \\
\hline 1592 & Trans-nerolidol [8] [13] [20] [28] & $\mathrm{rt} / \mathrm{MS}$ & $\begin{array}{l}- \\
-\end{array}$ & & - & & $16.16 \pm 10.01$ & 2 & - & & 4.364 & 0.225 \\
\hline
\end{tabular}

RI-retention index; rt/MS-identification by retention time and mass spectra, NIST-tentative identification by NIST11; SE-standard error; O-occurrence (i.e. the number of analyses in which the compounds was detected), ${ }^{*}$ compounds active on the antennae of EAG according to literature [10] [31]. The numbers in superscript after the VOC refers to the paper where it is identified as maize VOC.

the first time produce an insight of what might encounter a flying insect reaching a maize field. Our hypothesis that pests, such as ECB moths, are likely to be fairly tuned to the maize plant VOCs and probably use the specific volatile cues released by plant at the beginning of the night to reach oviposition site is supported by the diel 
variation evidenced in the results.

At the plant level, the relevant changes concerned the Z3-6:Ac that occurred only during dark period as well as the increase of limonene and p-cymene, newly identified in maize headspace. SQT were missing during the dark period and only detectable during daytime, in contrast of MT emission. The diel variations in MT and SQT emission is influenced by abiotic factors and are related to photosynthese activity as shown on other plants [15]-[19]. Another interesting information concern the MeSA identified as one of the main component in the headspace of healthy maize plants. The quantities fluctuate with the diel periodicity in the opposite way of the second main component the $\alpha$-copaene. MeSA in our results is not restricted as an herbivory induced component but appeared to be a constituent of the maize headspace. This result is reinforced with the results on maize field atmosphere in which this component is identified in large amount. MeSA can be considered as a key compound for maize plant recognition by ECB as it elicited high responses on female antennae [9] [13] and is active on female attraction behavior [10]. The most recurrent VOCs in maize headspace analyzes were MeSA, $\alpha$-pinene, p-cymene with limonene and $\alpha$-copene. The volatile pattern described here differed of the water stressed plant signal [10] and of the herbivore damaged plants [11]. The global change of VOCs in time may serve as different signals to host-seeking moths.

The maize field atmosphere VOCs analyzes showed that the natural chemical environment of host-seeking insect is poor in volatiles and is composed mainly of MeSA and MT. SQT were detected scarcely and without any apparent pattern. The most consistently detected VOCs in maize field atmosphere were MeSA, linalool and $\beta$-myrcene that were already reported as VOCs from maize but after herbivore damage, [8] [20] [21]. Additionally, limonene, $\alpha$-pinene, 3-carene were also repeatedly detected, but no information about their biological activity on ECB pests is known.

Linalool a previously identified compound from stressed or damaged maize plant was not detected in our VOC collection condition from healthy plant in the field. The emission of this compound by maize seemed to be a part of plant stress chemical signal. Linalool is generally released in large amounts from deciduous in forest [22] [23] and is likely coming from wooden hedges.

The apparent discrepancy between maize headspace and field atmosphere VOCs profiles concerned the patterns of MT and SQT. In the atmosphere VOCs collections the SQT were rarely detected and the distorted vision of SQT and MT ratio in atmosphere and plant were already described [22] [24]. The SQT are highly reactive with atmospheric $\mathrm{O}_{3}$ and are often completely destroyed in the atmosphere before they can be detected in an analysis [25] [26]. The average lifetime of a MT molecule in the air is about one hour and just 2 - 4 minutes for SQT [27]. The experimental design can also account for the differences. For the headspace VOCs collection we created a limited space, where the volatiles were concentrated, as for the atmosphere VOCs collections, the SPME fibers were exposed to field air with extremely low concentration of VOCs. Indeed, similar results were obtained by comparing the maize field and deciduous forest atmosphere VOCs compositions (Leppik \& Frérot, in-press).

As expected the chemical signal released by the maize plants differed with the diel periodicity. The pattern of the chemical signal encounter by nocturnal flying insect is specific to the dark period. The VOCs blends from maize headspace were mainly composed of MeSA and $\alpha$-copaene and Z3-6:Ac, MeSA, $\alpha$-pinene, 3-carene, p-cymene, limonene and DMNT were found in both maize headspace and atmosphere. They can be considered as candidate key compounds for host plant recognition and will deserve further studies on their insect behavioral relevance.

\section{Acknowledgements}

This work was supported by PhD fellowship from Archimedes Foundation (Estonia) and we gratefully acknowledge financial support from a grant Partenariat Hubert-Curien (PHC)_Parrot program (number 20668RB). The authors thank Aigi Margus (University of Tartu) for her assistance in volatile collections and Romain Linard for GC-MS analyses. As well Michel Lebars of Mortmoulin farm for access to the maize fields.

\section{References}

[1] Metcalf, R.L. and Metcalf, E.R. (1992) Plant Kairomones in Insect Ecology and Control. Chapman and Hall Ltd., London.

[2] Schoonhoven, L., Van Loon, J. and Dicke, M. (2005) Insect-Plant Biology. Oxford University Press, Oxford. 
[3] Caffrey, D.J. and Worthley, L. (1927) A Progress Report on the Investigations of the European Corn Borer. USDA Bulletin, 1548, 1-48.

[4] Showers, W.B., Reed, G., Robinson, J. and Derozari, M. (1976) Flight and Sexual Activity of the European Corn Borer. Environmental Entomology, 5, 1099-1104.

[5] Turlings, T.C. and Tumlinson, J.H. (1992) Systemic Release of Chemical Signals by Herbivore-Injured Corn. Proceedings of the National Academy of Sciences of the United States of America, 89, 8399-402. http://dx.doi.org/10.1073/pnas.89.17.8399

[6] Takabayashi, J., Takahashi, S., Dicke, M. and Posthumus, M. (1995) Developmental Stage of Herbivore Pseudaletia separata Affects Production of Herbivore-Induced Synomone by Corn Plants. Journal of Chemical Ecology, 21, 273287. http://dx.doi.org/10.1007/BF02036717

[7] Köllner, T.G., Schnee, C., Gershenzon, J. and Degenhardt, J. (2004) The Variability of Sesquiterpenes Emitted from Two Zea mays Cultivars Is Controlled by Allelic Variation of Two Terpene Synthase Genes Encoding Stereoselective Multiple Product Enzymes. Plant Cell, 16, 1115-1131. http://dx.doi.org/10.1105/tpc.019877

[8] D’Alessandro, M. and Turlings, T.C. (2005) In Situ Modification of Herbivore-Induced Plant Odors: A Novel Approach to Study the Attractiveness of Volatile Organic Compounds to Parasitic Wasps. Chemical Senses, 30, 739-753. http://dx.doi.org/10.1093/chemse/bji066

[9] Bengtsson, M., Karpati, Z., Reuveny, H., Yang, Z., Witzgall, P. and Szöcs, G. (2006) Flight Tunnel Responses of Z Strain European Corn Borer Females to Corn and Hemp Plants. Environmental Entomology, 35, 1238-1243. http://dx.doi.org/10.1603/0046-225X(2006)35[1238:FTROZS]2.0.CO;2

[10] Solé, J., Sans, A., Riba, M. and Guerrero, A. (2010) Behavioural and Electrophysiological Responses of the European Corn Borer Ostrinia nubilalis to Host-Plant Volatiles and Related Chemicals. Physiological Entomology, 35, 354-363. http://dx.doi.org/10.1111/j.1365-3032.2010.00750.x

[11] Turlings, T.C., Loughrin, J., Mccall, P., Röse, U., Lewis, W. and Tumlinson, J.H. (1995) How Caterpillar-Damaged Plants Protect Themselves by Attracting Parasitic Wasps. Proceedings of the National Academy of Sciences of the United States of America, 92, 4169-4174. http://dx.doi.org/10.1073/pnas.92.10.4169

[12] Degen, T., Dillmann, C., Marion-Poll, F. and Turlings, T.C. (2004) High Genetic Variability of Herbivore-Induced Volatile Emission within a Broad Range of Maize Inbred Lines. Plant Physiology, 135, 1928-1938. http://dx.doi.org/10.1104/pp.104.039891

[13] Leppik, E. and Frérot, B. (2012) Volatile Organic Compounds and Host-Plant Specialization in European Corn Borer E and Z Pheromone Races. Chemoecology, 22, 119-129. http://dx.doi.org/10.1007/s00049-012-0104-Z

[14] Lancanshire, P., Bleiholder, H., Vandemboom, T., Langelüddeke, P., Strauss, R., Weber, E. and Witzenberger, A. (1991) A Uniform Decimal Code for Growth Stages of Crops and Weeds. Annals of Applied Biology, 119, 561-601. http://dx.doi.org/10.1111/j.1744-7348.1991.tb04895.x

[15] Fall, R., Karl, T., Hansel, A., Jordan, A. and Lindiger, W. (1999) Volatile Organic Compounds Emitted after Leaf Wounding: On-Line Analysis by Proton-Transfer-Reaction Mass Spectrometry. Journal of Geophysical Research, 104, 15963-15974. http://dx.doi.org/10.1029/1999JD900144

[16] Fuentes, J., Lerdau, M., Atkinson, R., Baldocchi, D., Bottenheim, J., Ciccioli, P., Lamb, B., Geron, C., Gu, L. and Guenther, A. (2000) Biogenic Hydrocarbons in the Atmospheric Boundary Layer: A Review. Bulletin of the American Meteorological Society, 81, 1537-1576. http://dx.doi.org/10.1175/1520-0477(2000)081<1537:BHITAB>2.3.CO;2

[17] Duhl, T., Helmig, D. and Guenther, A. (2008) Sesquiterpene Emissions from Vegetation: A Review. Biogeosciences, 5, 761-777. http://dx.doi.org/10.5194/bg-5-761-2008

[18] Grote, R. and Niinemets, U. (2008) Modeling Volatile Isoprenoid Emissions-A Story with Split Ends. Plant Biology (Stuttg), 10, 8-28. http://dx.doi.org/10.1055/s-2007-964975

[19] Sharkey, T.D., Wiberley, A. and Donohue, A. (2008) Isoprene Emission from Plants: Why and How. Annals of Botany, 101, 5-18.

[20] Turlings, T.C., Lengwiler, U., Bernasconi, M. and Wechsler, D. (1998) Timing of Induced Volatile Emissions in Maize Seedlings. Planta, 207, 146-152. http://dx.doi.org/10.1007/s004250050466

[21] Ozawa, R., Shiojiri, K., Sabelis, M. and Takabayashi, J. (2008) Maize Plants Sprayed with Either Jasmonic Acid or Its Precursor, Methyl Linolenate, Attract Armyworm Parasitoids, but the Composition of Attractants Differs. Entomologia Experimentalis et Applicata, 129, 189-199. http://dx.doi.org/10.1111/j.1570-7458.2008.00767.x

[22] Ciccioli, P., Brancaleoni, E., Frattoni, M., Di Palo, V., Valentini, R., Tirone, G., Seufert, G., Bertin, N., Hansen, U. and Csiky, O. (1999) Emission of Reactive Terpene Compounds from Orange Orchards and Their Removal by WithinCanopy Processes. Journal of Geophysical Research, 104, 8077-8094.

[23] Owen, S.M., Boissard, C. and Hewitt, C.N. (2001) Volatile Organic Compounds (VOCs) Emitted from 40 Mediterra- 
nean Plant Species: VOC Speciation and Extrapolation to Habitat Scale. Atmospheric Environment, 35, 5393-5409. http://dx.doi.org/10.1016/S1352-2310(01)00302-8

[24] Bouvier-Brown, N., Goldstein, A., Gilman, J., Kuster, W. and De Gouw, J. (2009) In-Situ Ambient Quantification of Monoterpenes, Sesquiterpenes, and Related Oxygenated Compounds during BEARPEX 2007: Implications for Gasand Particle-Phase Chemistry. Atmospheric Chemistry and Physics, 9, 5505-5518.

[25] Atkinson, R. (1990) Gas-Phase Tropospheric Chemistry of Organic Compounds: A Review. Atmospheric Environment. Part A. General Topics, 24, 1-41. http://dx.doi.org/10.1016/0960-1686(90)90438-S

[26] Bonn, B. and Moortgat, G.K. (2003) Sesquiterpene Ozonolysis: Origin of Atmospheric New Particle Formation from Biogenic Hydrocarbons. Geophysical Research Letters, 30, 1585-1589. http://dx.doi.org/10.1029/2003GL017000

[27] Kesselmeier, J. and Staudt, M. (1999) Biogenic Volatile Organic Compounds (VOC): An Overview on Emission, Physiology and Ecology. Journal of Atmospheric Chemistry, 33, 23-88.

[28] Degen, T., Dillmann, C., Marion-Poll, F. and Turlings, T.C. (2004) High Genetic Variability of Herbivore-Induced Volatile Emission within a Broad Range of Maize Inbred Lines. Plant Physiology, 135, 1928-1938. http://dx.doi.org/10.1104/pp.104.039891

[29] Buttery, R.G. and Ling, L.C. (1984) Corn Leaf Volatiles: Identification Using Tenax Trapping for Possible Insect Attractants. Journal of Agricultural and Food Chemistry, 32, 1104-1106.

[30] Köllner, T.G., Schnee, C., Gershenzon, J. and Degenhardt, J. (2004) The Sesquiterpene Hydrocarbons of Maize (Zea mays) form Five Groups with Distinct Developmental and Organ-Specific Distributions. Phytochemistry, 65, 18951902. http://dx.doi.org/10.1016/j.phytochem.2004.05.021

[31] Bengtsson, M., Jaastad, G., Knudsen, G. and Kobro, S. (2006) Plant Volatiles Mediate Attraction to Host and NonHost Plant in Apple Fruit Moth, Argyresthia Conjugella. Entomologia Experimentalis et Applicata, 118, 77-85. 